\title{
Transient simulations of the present and the last interglacial climate using the Community Climate System Model version 3: effects of orbital acceleration
}

\author{
Vidya Varma $^{1, a}$, Matthias Prange ${ }^{1,2}$, and Michael Schulz ${ }^{1,2}$ \\ ${ }^{1}$ MARUM - Center for Marine Environmental Sciences, University of Bremen, Bremen, Germany \\ ${ }^{2}$ Faculty of Geosciences, University of Bremen, Bremen, Germany \\ ${ }^{a}$ now at: National Institute of Water and Atmospheric Research, Wellington, New Zealand
}

Correspondence to: Vidya Varma (vidya.varma@niwa.co.nz)

Received: 28 June 2015 - Published in Geosci. Model Dev. Discuss.: 21 July 2015

Revised: 2 October 2016 - Accepted: 5 October 2016 - Published: 1 November 2016

\begin{abstract}
Numerical simulations provide a considerable aid in studying past climates. Out of the various approaches taken in designing numerical climate experiments, transient simulations have been found to be the most optimal when it comes to comparison with proxy data. However, multimillennial or longer simulations using fully coupled general circulation models are computationally very expensive such that acceleration techniques are frequently applied. In this study, we compare the results from transient simulations of the present and the last interglacial with and without acceleration of the orbital forcing, using the comprehensive coupled climate model CCSM3 (Community Climate System Model version 3). Our study shows that in low-latitude regions, the simulation of long-term variations in interglacial surface climate is not significantly affected by the use of the acceleration technique (with an acceleration factor of 10) and hence, large-scale model-data comparison of surface variables is not hampered. However, in high-latitude regions where the surface climate has a direct connection to the deep ocean, e.g. in the Southern Ocean or the Nordic Seas, accelerationinduced biases in sea-surface temperature evolution may occur with potential influence on the dynamics of the overlying atmosphere.
\end{abstract}

\section{Introduction}

Earth's past climate is simulated numerically through either equilibrium simulations (time slice experiments) or through transient simulations with time-dependent boundary conditions using climate models. In equilibrium simulations, the boundary conditions are not varied temporally but rather kept fixed under the assumption that the Earth system is in equilibrium with them (e.g. Braconnot et al., 2007; Lunt et al., 2013; Milker et al., 2013; Rachmayani et al., 2016). Evidently, only limited information regarding the temporal evolution of the dynamic system is obtained by the time slice approach. This approach significantly reduces the computational expenses for the otherwise costly multi-millennial or longer transient simulations, which involve temporally varying boundary conditions.

Another approach to bypass the expensive transient simulations using coupled general circulation models (CGCMs) is by using Earth System Models of Intermediate Complexity (EMICs), which describe the dynamics of the atmosphere and/or ocean with simplified physics. EMICs are simple enough to allow long-term climate simulations over several thousands of years or even glacial cycles prescribing or parameterizing many of the dynamical processes that are explicitly resolved in CGCMs (Claussen et al., 2002). However, in studies that require more realistic simulation of physical processes and high spatial resolution, the use of comprehensive CGCMs is inevitable. 


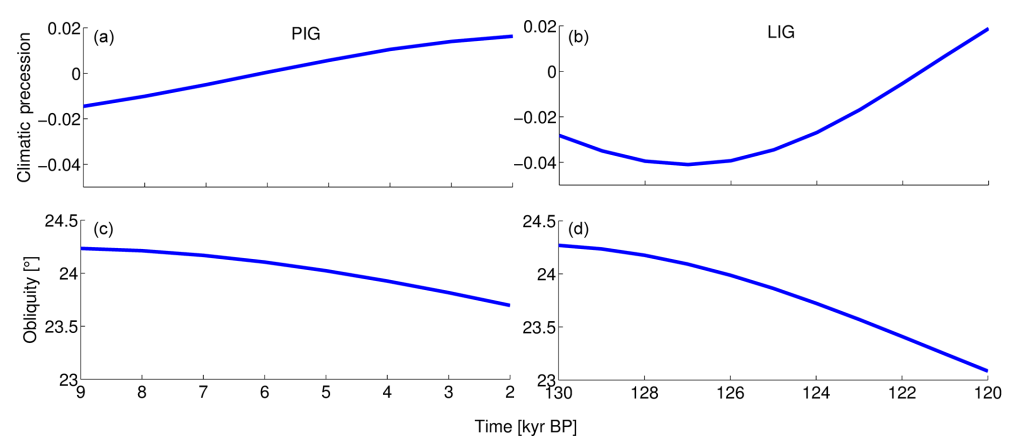

Figure 1. Orbital parameters in the transient experiments for the PIG (a, c) and the LIG (b, d) (Berger, 1978).

When it comes to comparison of the model results with proxy data, transient simulations give a superior insight compared to time slice experiments, since all of the available data (time series) can be used, whereas model-data comparison with time slice experiments makes use of only a small fraction of all available data. This also implies that transient simulations allow the application of the whole spectrum of statistical methods for spatiotemporal data analysis for modeldata comparison, thus offering a much stronger assessment of the model performance as well as the data quality (e.g. Liu et al., 2014; Otto-Bliesner et al., 2014; Voigt et al., 2015).

Transient simulations using comprehensive CGCMs are hugely affected by model speed restrictions and often "acceleration techniques" are adopted for multi-millennial (or longer) palaeoclimate simulations (e.g. Lorenz and Lohmann, 2004; Varma et al., 2012; Smith and Gregory, 2012; Bakker et al., 2014; Kwiatkowski et al., 2015). Specifically, acceleration of slowly varying orbital variations has been employed. Earlier studies have already been conducted to test the undesired effects of acceleration techniques in the boundary conditions on climate simulations, but have used EMICs only (Lunt et al., 2006; Timm and Timmermann, 2007). In this study, we employ a comprehensive CGCM to examine the evolution of basic climate parameters under temporally varying orbital forcing for the present and last interglacial periods, using transient simulations with and without acceleration of the external forcing. The basic assumption for the application of this acceleration technique is that orbital forcing operates on much longer timescales than those inherent in the atmosphere and upper ocean layers (Lorenz and Lohmann, 2004).

\section{Methods}

Multi-millennial transient simulations were performed using the comprehensive global CGCM CCSM3 (Community Climate System Model version 3). NCAR's (National Center for Atmospheric Research) CCSM3 is a state-of-the-art fully coupled model, composed of four separate components representing atmosphere, ocean, land and sea ice (Collins et al.,
2006). Here, we employ the low-resolution version described in detail by Yeager et al. (2006). In this version, the resolution of the atmospheric component is given by T31 $\left(3.75^{\circ}\right.$ transform grid), with 26 layers in the vertical, while the ocean has a nominal resolution of $3^{\circ}$ with refined meridional resolution $\left(0.9^{\circ}\right)$ around the equator and a vertical resolution of 25 levels. The sea-ice component shares the same horizontal grid with the ocean model.

The time periods of interest in this study are the present interglacial (PIG) (11.7-0 kyr BP, kiloyears before present) and the last interglacial (LIG) (ca. 130-115 kyr BP). On these multi-millennial timescales, it is the periodic changes in the Earth's orbital parameters that cause the modifications of seasonal and latitudinal distribution of insolation at the top of the atmosphere (Berger, 1978), acting as the prime forcing of long-term interglacial climate change.

The climatic precession parameter increased during both the PIG and the LIG (from $\sim 127 \mathrm{kyr}$ BP onward; Fig. 1). As a result, there was a weakening of the seasonal insolation amplitude in the Northern Hemisphere resulting in a decrease in the boreal summer insolation (Berger, 1978). For the LIG, the variability in climatic precession was more pronounced compared to the PIG due to a larger orbital eccentricity. Hence, the effect of orbital forcing on climate is expected to be stronger (Fig. 1b). Additionally, the obliquity decreased by $\sim 0.5$ to $1^{\circ}$ over the interglacials resulting in a decrease of insolation in the summer hemisphere as well as total annual insolation at southern and northern high latitudes (Loutre et al., 2004). We note that the total annual insolation at a given latitude does not depend on precession.

Accelerated and non-accelerated transient simulations covering the two interglacials ( 9 to $2 \mathrm{kyr} \mathrm{BP}$ for the PIG and 130 to $120 \mathrm{kyr}$ BP for the LIG) were carried out under varying orbital forcing only. The experimental setups for the accelerated PIG and LIG simulations are described in Varma et al. (2012) and Bakker et al. (2013), respectively. In both simulations, the orbital forcing is accelerated by a factor of 10 (the orbital parameters were changed every 10 model years, but with 100-year forward time steps). Therefore, climate trends over 7000 (PIG experiment) and 10000 years (LIG experiment) imposed by the external orbitally driven insola- 
tion changes, are represented in the accelerated experiments by only 700 and 1000 simulation years, respectively.

Throughout all runs, pre-industrial aerosol and ozone distributions as well as modern ice sheet configurations were prescribed. The greenhouse gas concentrations in the LIG runs take the mean value for the period 130-120 kyr BP (i.e. $\mathrm{CO}_{2}=272 \mathrm{ppm}, \mathrm{CH}_{4}=622 \mathrm{ppb}$ and $\mathrm{N}_{2} \mathrm{O}=259 \mathrm{ppb}$; Loulergue et al., 2008; Lüthi et al., 2008; Spahni et al., 2005). Throughout the PIG experiments, greenhouse gas concentrations were kept constant at pre-industrial values $\left(\mathrm{CO}_{2}=280 \mathrm{ppm}, \mathrm{CH}_{4}=760 \mathrm{ppb}\right.$ and $\left.\mathrm{N}_{2} \mathrm{O}=270 \mathrm{ppb}\right)$.

Initialization of the accelerated and the non-accelerated PIG transient simulation was identical: from a pre-industrial quasi-equilibrium simulation (Merkel et al., 2010), the model was integrated for 400 years with fixed boundary conditions representing $9 \mathrm{kyr} \mathrm{BP}$ orbital forcing and pre-industrial atmospheric composition. Both transient simulations started from the final state of this time slice run. The LIG transient simulations were initialized as follows: the final state of the $9 \mathrm{kyr}$ BP simulation was used to initialize a $130 \mathrm{kyr}$ BP time slice run. This $130 \mathrm{kyrBP}$ run was integrated for another 400 years with fixed boundary conditions representing $130 \mathrm{kyr}$ BP orbital forcing and atmospheric composition as in the transient LIG runs (see above), which were then started from the final 130 kyr BP state. We note that 400 years of spinup were not enough to bring the deep ocean to a perfectly steady state.

Forcing of accelerated and non-accelerated transient runs differs only in the rate of change of orbital parameters (similar to the accelerated runs, orbital parameters were updated every 10 integration years also in the non-accelerated simulations). This approach allows the identification of acceleration effects by direct comparison of the accelerated and non-accelerated runs.

For the analyses of the model results decadal means (referring to model years) have been used from all the transient simulations. Differences between time series from accelerated and non-accelerated runs were calculated using the following approach: serial 100-year averages have been calculated from the non-accelerated simulations, such that the 7000 years of the PIG experiment are represented by 70 points in time. The 70 decadal mean values from the accelerated PIG run were mapped onto the orbital timescale, i.e. the first decadal mean represents the first 100 orbital years of the PIG, the second decadal mean represents the second 100 orbital years of the PIG, and so on (in other words, a 10 -year average in model years is stretched to represent a 100 years). The same approach was used to calculate differences between accelerated and non-accelerated simulations of the LIG, where we subtract 100 100-year averages from the non-accelerated simulation from 100 10-year averages from the accelerated simulation.

The main focus of our analysis is on the basic climate fields surface temperature and precipitation. In addition, we analyse the evolution of global deep-ocean temperature and sea ice in order to elucidate high-latitude features we observe in the sea-surface temperature fields, as well as low-level $(850 \mathrm{hPa})$ zonal wind in order to assess the potential impact of sea-surface temperature biases on atmosphere dynamics.

To investigate and visualize spatiotemporal climate variability we employ Hovmöller diagrams and empirical orthogonal function (EOF) analysis. The EOFs (or principal components) were found by computing the eigenvalues and eigenvectors of the covariance matrix of a climatic field (e.g. von Storch and Zwiers, 2004). The derived eigenvalues provide a measure of the percent variance explained by each mode (the first or leading mode provides the highest variance in the analysed field). The time series of each mode were obtained by projecting the derived eigenvectors onto the spatially weighted anomalies.

\section{Results}

Figure 2 shows the simulated evolution of annual mean global ocean temperatures at depths of $4 \mathrm{~m}$ (surface), 437 and $1884 \mathrm{~m}$ for both interglacials. The surface temperature for the PIG shows considerable differences between the accelerated and non-accelerated runs, especially during the early to middle PIG (Fig. 2a). While there is a pronounced decreasing trend in surface temperature for the non-accelerated run during the time period 9-7 kyr BP, this is not captured in the accelerated PIG run. The $437 \mathrm{~m}$ temperature evolution for the PIG shows reasonably similar trends in both accelerated and non-accelerated simulations (Fig. 2c). However, at deeper levels $(1884 \mathrm{~m})$ there is an overall significant difference quantitatively between the accelerated and non-accelerated PIG runs (Fig. 2e). While there is a drop of $\sim 0.4{ }^{\circ} \mathrm{C}$ in the deep-ocean temperature in the non-accelerated simulation during the early PIG, the accelerated run is underestimating this decreasing trend and shows a strongly delayed and much more stable response.

For the LIG, the temperatures at the surface and at $437 \mathrm{~m}$ depths show overall similar responses in both accelerated and non-accelerated runs, though there are some differences during the late LIG (Fig. 2b and d). However, like in the PIG, the response of $1884 \mathrm{~m}$ temperature is quite contrasting in the LIG as well (Fig. 2f). The deep-ocean temperature is showing a decreasing trend during the early to middle LIG and then an increasing trend for the middle to late LIG in the non-accelerated run (Fig. 2f). Not only is this trend variability missing in the accelerated run but also the general temperature evolution during the LIG is quantitatively underestimated. While the change in $1884 \mathrm{~m}$ temperature during the LIG is $\sim 0.3{ }^{\circ} \mathrm{C}$ in the non-accelerated simulation, it is just about $0.06^{\circ} \mathrm{C}$ in the accelerated run (Fig. $2 \mathrm{f}$ ).

Figure 3 represents the evolution of zonally averaged surface temperature for both interglacials. For the PIG, in response to orbital forcing, it is the high latitudes that show a robust cooling response in both accelerated and nonaccelerated simulations (Fig. 3a and b). It also shows a warm- 

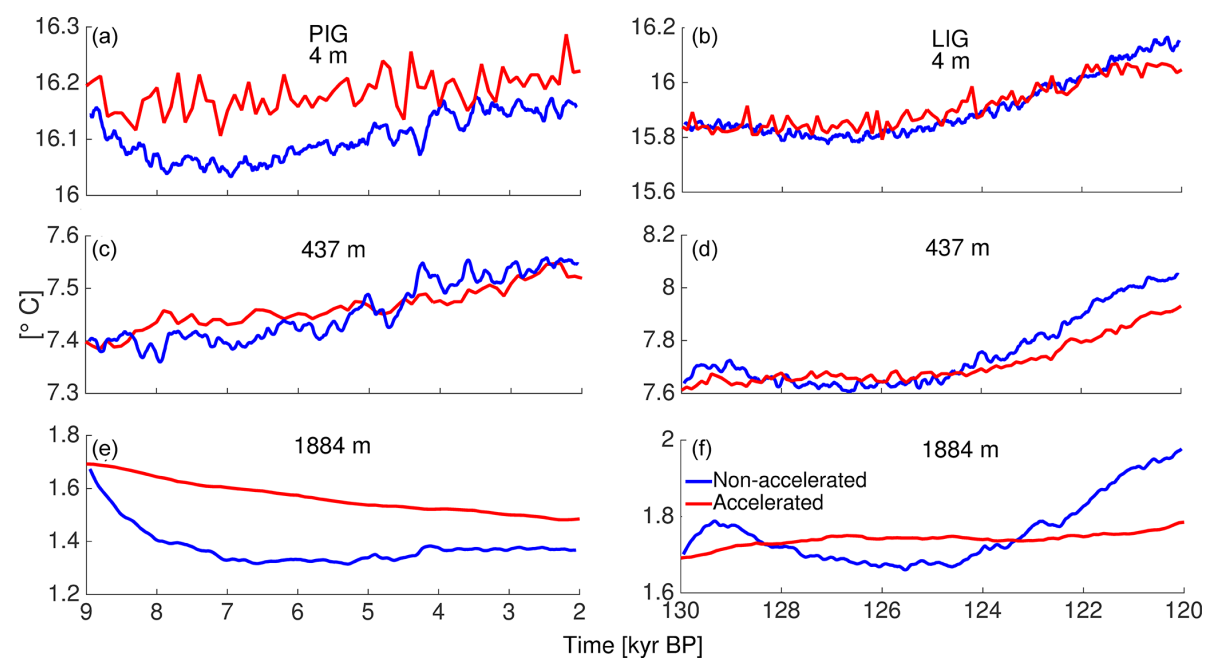

Figure 2. Evolution of global mean potential ocean temperature at various depths for the PIG (a, c, e) and the LIG (b, d, f). Blue lines represent the non-accelerated simulations and red lines represent the accelerated simulations. All plots were created using the decadal mean values (referring to model years). In addition, a 10-point running average was applied to the decadal mean values of the non-accelerated simulations. Time series of the accelerated runs were mapped onto orbital time axes by linear interpolation, such that 10 model years represent 100 orbital years.

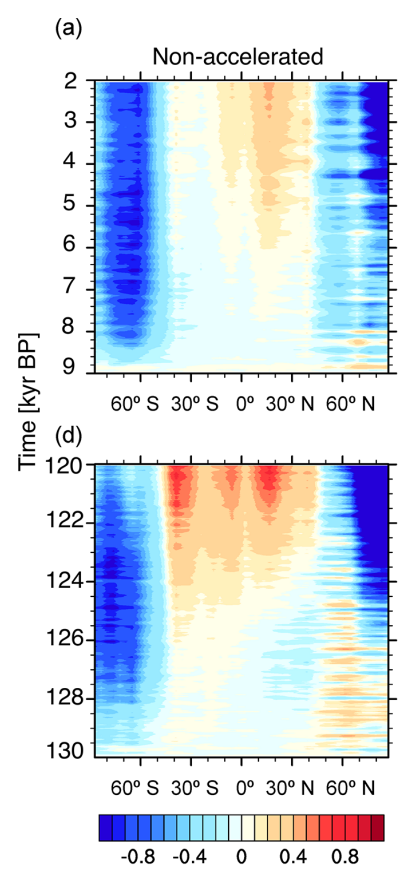

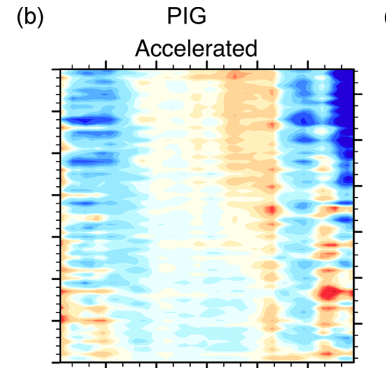

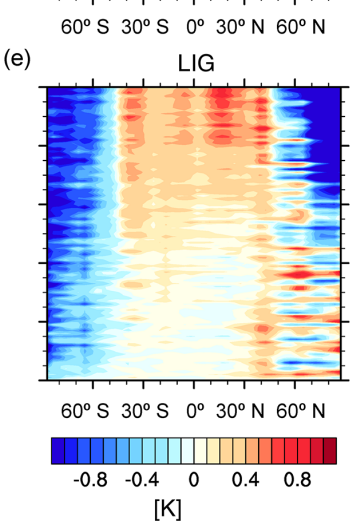

(c)

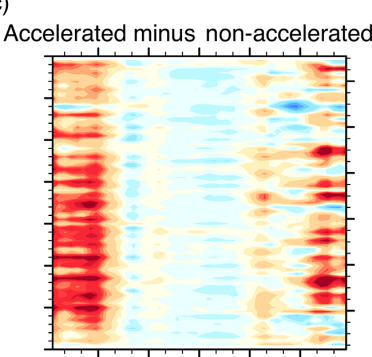

$60^{\circ} \mathrm{S} 30^{\circ} \mathrm{S} 0^{\circ} 30^{\circ} \mathrm{N} 60^{\circ} \mathrm{N}$

(f)

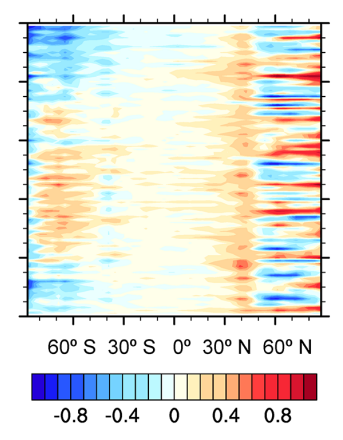

Figure 3. Evolution of zonally averaged surface temperature anomalies (including ocean and land) during interglacials for both nonaccelerated (a, d) and accelerated (b, e) simulations. Shown are anomalies relative to $9 \mathrm{kyr}$ BP (PIG) and 130 kyr BP (LIG). Differences in the temperature evolution between accelerated and non-accelerated simulations are also displayed (c, f). All plots were created using the decadal mean values (referring to model years). In addition, a 10-point running average was applied to the decadal mean values of the non-accelerated simulations. See the main text (Sect. 2) for the calculation of differences (c, $\mathbf{f}$ ).

ing of the tropics during the middle to late PIG in both of the simulations. The anomaly between simulations with and without orbital acceleration (Fig. 3c) clearly shows that there are evident disparities in the high latitudes especially dur- ing the early to middle PIG, when the southern high-latitude cooling in the accelerated simulation lags (and underestimates) the cooling in the non-accelerated run. For the LIG, the northern high latitudes tend to show a slight warming 

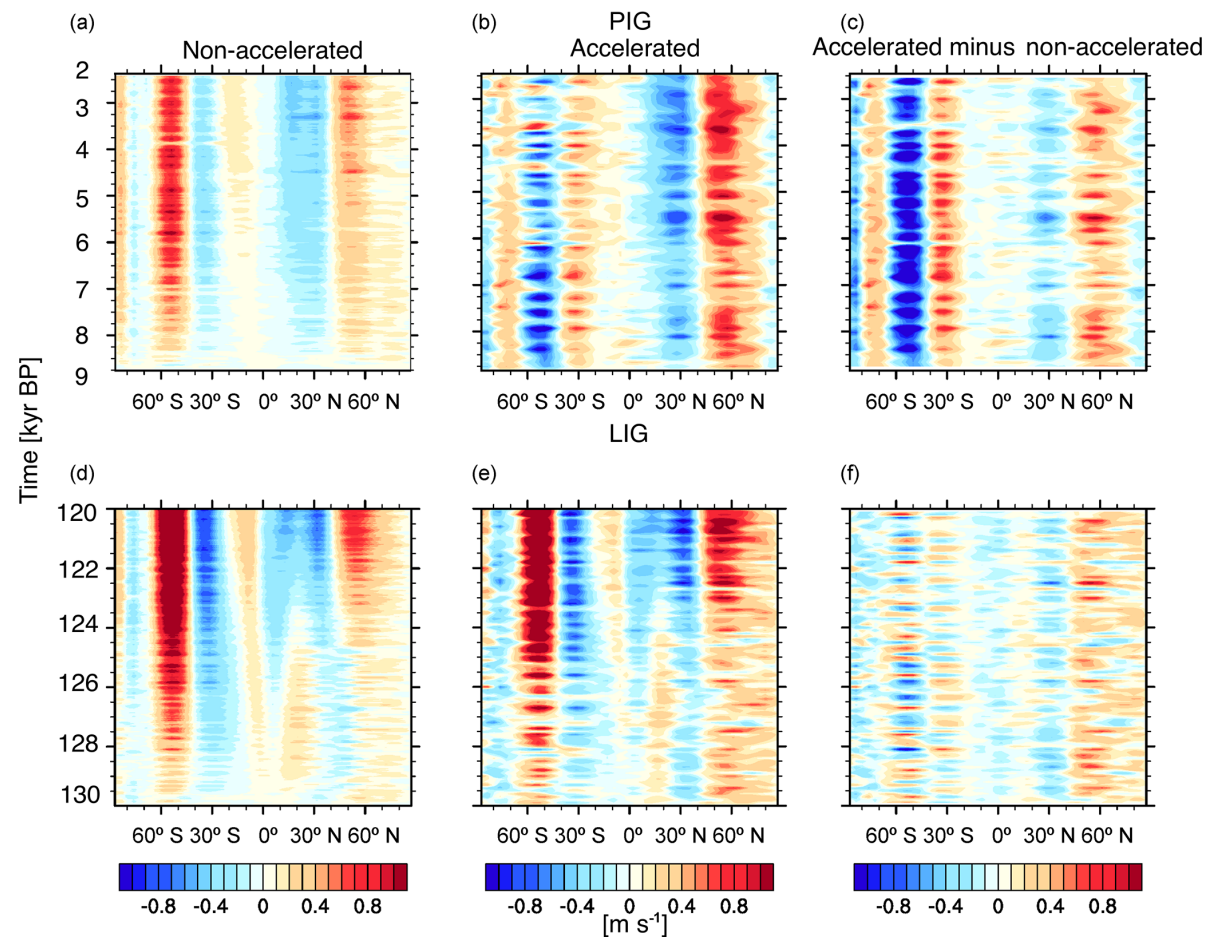

(f)

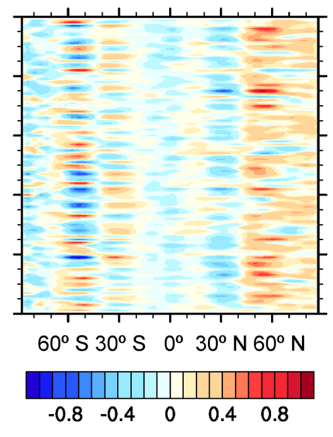

Figure 4. Same as Fig. 3 but for $850 \mathrm{hPa}$ zonal wind.

between $\sim 130$ and $125 \mathrm{kyr} \mathrm{BP}$ and then an intense cooling trend afterwards in both non-accelerated and accelerated simulations (Fig. 3d and e). The southern high latitudes show a cooling trend during the early LIG in the non-accelerated run, followed by a warming trend during the late LIG. By contrast, a steady cooling trend in the southern high latitudes is simulated in the accelerated run. The low latitudes show strongest warming from middle to late LIG in both of the simulations.

Figure 4 displays the evolution of zonally averaged zonal wind at $850 \mathrm{hPa}$ for both interglacials. A pronounced strengthening of the zonal wind circulation in the southern high midlatitudes (ca. 50-60 $\mathrm{S}$ ) is simulated in the nonaccelerated PIG run (Fig. 4a). There is a similar trend observed in the accelerated simulation as well but less intense and delayed in time compared to its non-accelerated counterpart (Fig. 4b). This wind intensification at the southern flank of the southern westerly wind (SWW) belt is accompanied by a decrease of zonal wind speed at the northern flank of the SWW region (ca. 30-40 $\mathrm{S}$ ), which can be depicted as a general poleward shift of the SWW during the PIG under orbital forcing as described in an earlier study (Varma et al., 2012). Similarly, during the LIG a poleward shift of the SWW under orbital forcing is observed in both non-accelerated and accelerated simulations as well, albeit more robust compared to the PIG response (Fig. $4 \mathrm{~d}$ and e). Meanwhile, the Northern Hemisphere westerly winds appear to shift northward (weakening of the winds around $30^{\circ} \mathrm{N}$ and strengthening around $50-60^{\circ} \mathrm{N}$ ), the northeast trade winds (south of ca. $20^{\circ} \mathrm{N}$ in the Northern Hemisphere) become stronger and the southeast trade winds (north of ca. $20^{\circ} \mathrm{S}$ ) weaken during all the interglacial simulations. The changing trade winds indicate a southward shift of the global mean intertropical convergence zone throughout the PIG and the LIG (cf. Schneider et al., 2014).

Figure 5 shows the evolution of global surface temperature during the PIG, for both non-accelerated and accelerated runs decomposed into EOFs. The first EOF shows a general cooling trend of the high latitudes in both hemispheres in both non-accelerated and accelerated simulations. The cooling is more pronounced in the northern high latitudes in response to the changes in insolation. Maximum cooling is observed around Baffin Bay extending up to the Labrador Sea in both of the simulations (Fig. 5a and e). Sea-ice effects play a role here in amplifying the climatic response to the orbital forcing, as evident from the first EOF of sea-ice concentration (Fig. 6). Another feature observed in both simulations is the general warming trend in the tropics, especially over the Sahel and Indian regions, which is mainly attributed to climate feedbacks associated with orbital-induced weakening of the monsoons (e.g. Bakker et al., 2013). The second EOF shows strong variability in the Nordic Seas, associated with shifts in the sea-ice margin in both non-accelerated and accelerated simulations (Figs. 5c, g and 6c, g).

Even though the general spatial patterns of the two leading EOFs are similar between the accelerated and the non- 
(a)

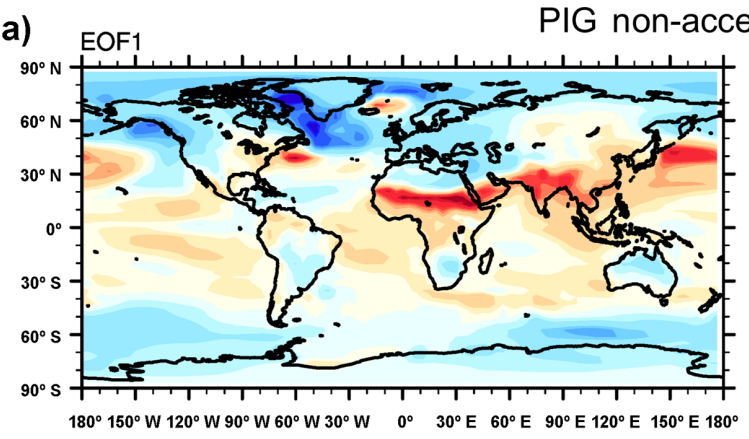

(c)

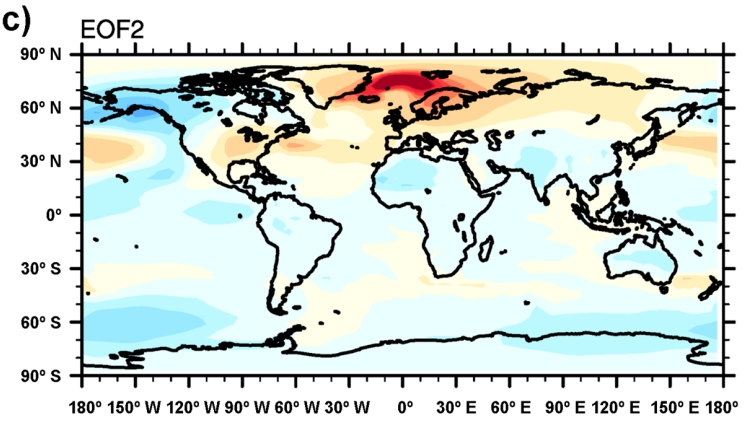

(b)

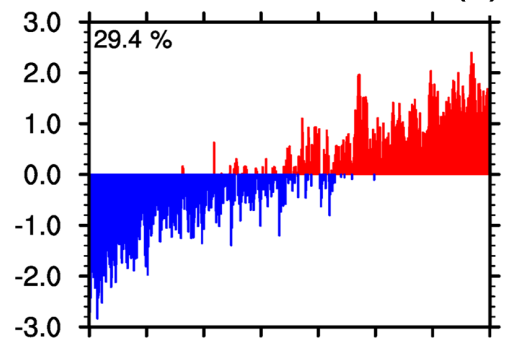

(d)

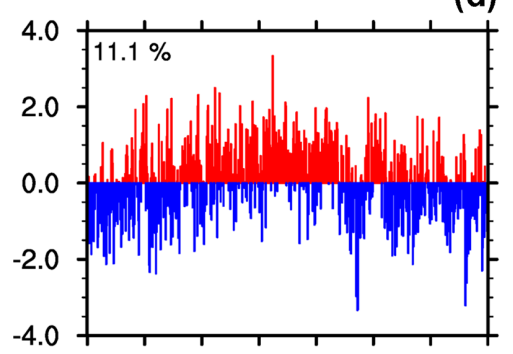

(e)

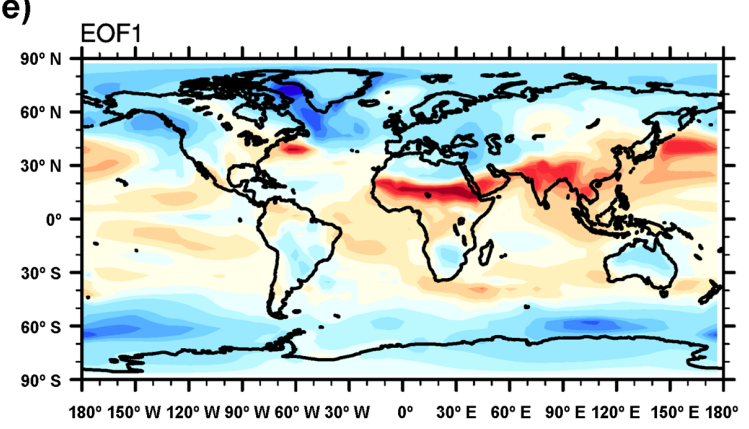

(g)

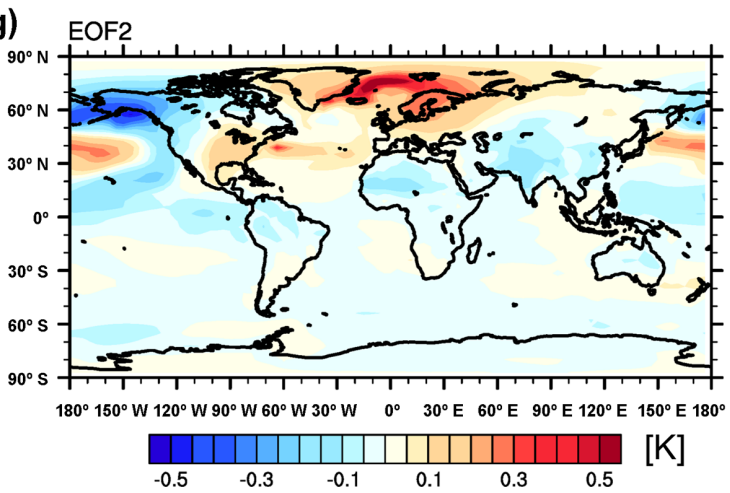

(f)

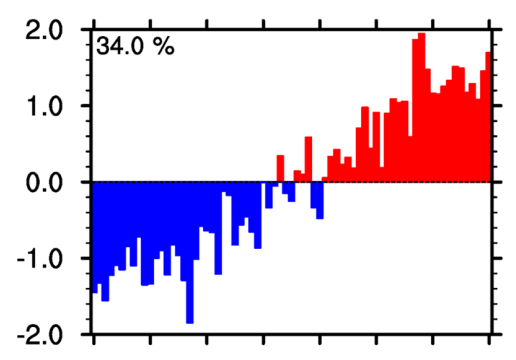

(h)

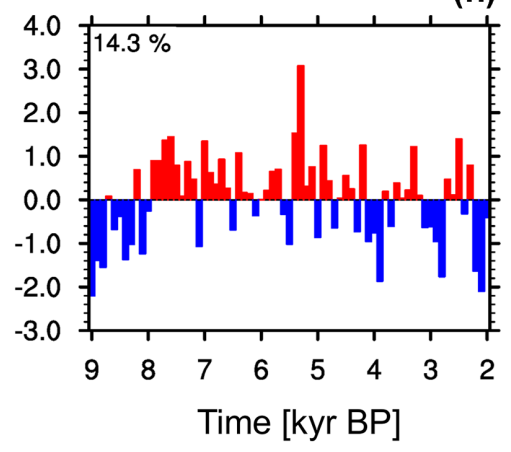

Figure 5. Leading two EOFs of annual mean surface temperature calculated from the non-accelerated (a-d) and accelerated (e-h) PIG simulations. Explained variances of each EOF are specified in the principal component (time series) plots $(\mathbf{b}, \mathbf{d}, \mathbf{f}, \mathbf{h})$. All EOF analyses were performed on serial decadal mean values (referring to model years) from the transient simulations. Principal components are standardized and the EOF maps (a, $\mathbf{c}, \mathbf{e}, \mathbf{g}$ ) were obtained by regressing the surface temperature data onto the corresponding standardized principal component time series. 
(a)

PIG non-accelerated

(b)


(c)

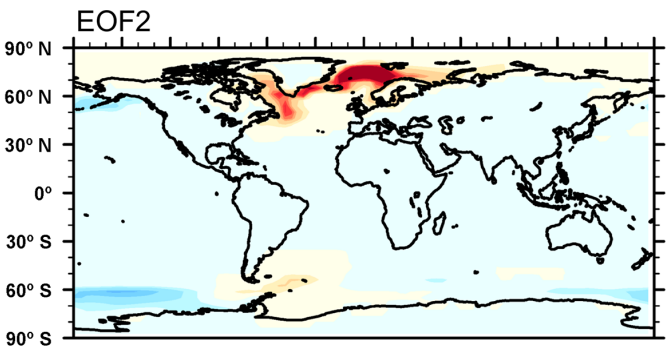

(d)

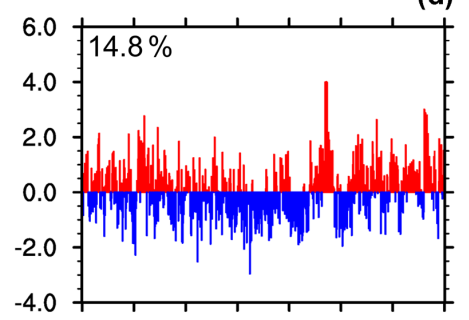

(e)

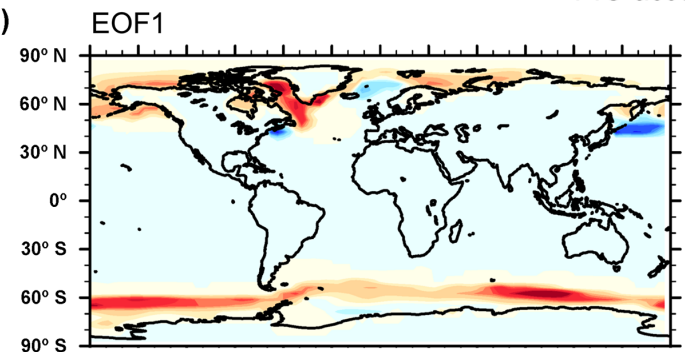

PIG accelerated

(f)


(h)

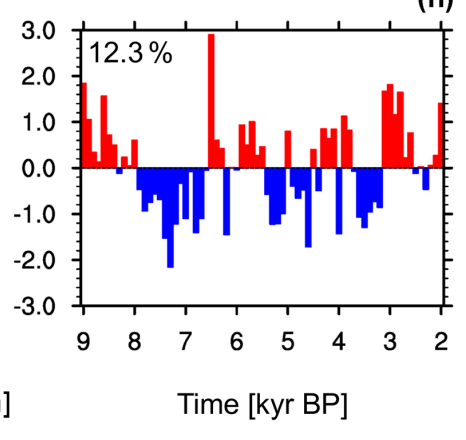

Figure 6. Same as Fig. 5 but for PIG sea-ice concentration.

accelerated simulation, some differences in the EOF maps are evident especially in the northern North Atlantic and Nordic Seas as well as in the Southern Ocean. Moreover, the first principal component exhibits a rather linear trend throughout the Holocene in the accelerated simulation (Fig. 5f), whereas an increased rate of change can be observed during the early Holocene in the first principal component of the non-accelerated run (Fig. 5b).

The spatiotemporal evolution of global surface temperature during the LIG is represented in Fig. 7 by means of the two leading EOFs. The observed high-latitude cooling in the Northern Hemisphere is more pronounced in the LIG compared to the PIG in line with larger insolation changes. Similar is the case with the tropics where the warming is more pronounced compared to the PIG. These patterns are very similar in the first EOFs of both non-accelerated and accelerated simulations (Fig. 7a and e). The second EOFs reflect strong variability in the northern North Atlantic. As for PIG, sea-ice variations are closely related to high-latitude surface temperature variability (Fig. 8). In general, both non-accelerated and accelerated simulations share similar response patterns in the second EOF (Fig. 7c and g). However, both leading EOFs reveal pronounced differences between non-accelerated and accelerated runs in the Southern Ocean 
sector, similar to what has been found for the PIG simulations.

Figure 9 shows the leading two EOFs for global precipitation during the PIG for both non-accelerated and accelerated simulations. The first EOF of both simulations reveals a general weakening of the north African and Indian monsoon systems along with a strengthening of Southern Hemisphere monsoons (Fig. 9a and e). The second EOF does not contain a long-term (orbitally driven) trend, but rather shows a pattern of (multi-)decadal tropical precipitation variability. This EOF is not significantly affected by the acceleration either.

Figure 10 depicts the evolution of global precipitation during the LIG in both non-accelerated and accelerated simulations. Similar to the PIG, there is a decreasing trend in north African and Indian monsoonal rainfall along with increasing precipitation over South America, southern Africa and Australia (Fig. 10a and e), albeit more pronounced than during the PIG. The second EOF contains a long-term (orbitally forced) signal, but explains only ca. $8 \%$ of the total variance in both the accelerated and the non-accelerated run. Again, orbital acceleration hardly affects the precipitation EOFs.

Figure 11 displays the temporal evolution of the Atlantic meridional overturning circulation (AMOC) during both interglacials. During the PIG, the AMOC generally shows a decreasing trend, whereas an increasing trend is simulated for the LIG. The long-term LIG AMOC trend is hardly affected by the acceleration. Overall, the AMOC shows relatively small changes in all experiments. Therefore, shifts in rainfall in tropical/monsoonal regions and global surface temperature patterns are (to first order) free from internal AMOC-related changes.

\section{Discussion}

Our analysis of time series and EOF patterns has shown that the interglacial evolution of simulated surface climate variables (temperature, precipitation, wind) is hardly affected by the application of an orbital acceleration factor of 10 in low latitudes, whereas noticeable differences may arise in extratropical regions. The regional biases resulted in accelerationinduced global mean sea-surface temperature biases of about $0.05-0.1^{\circ} \mathrm{C}$ during the early to middle PIG and the late LIG in our simulations (Fig. 2). To further specify the regions where acceleration-induced biases are greatest, we calculated global maps of root mean square differences between the accelerated and the non-accelerated runs over the low-pass filtered surface temperature time series for the PIG and the LIG (Fig. 12). For the PIG, the largest acceleration-induced biases are found in the Southern Ocean and the Nordic Seas, i.e. regions where the surface climate has a direct connection to the deep ocean (upwelling of deep water in the Southern Ocean, deep convection regions in the northern and southern high latitudes). Acceleration-induced biases in these highlatitude regions are further amplified by sea-ice feedbacks (cf. Timmermann et al., 2014). A qualitatively similar result is found for the LIG (Fig. 12b); however, the Northern Hemisphere maximum has shifted to the northern North Atlantic. This is because deep convection disappears from the Nordic Seas in the LIG simulations associated with excessive sea ice. Instead, deep convection and hence deep-water formation mostly takes place south of the Denmark Strait in both the accelerated and the non-accelerated LIG runs (not shown). In general, root mean square deviations are larger during the PIG than during the LIG; in other words, PIG climate simulations appear more susceptible to acceleration-induced biases than LIG simulations. We hypothesize that the stronger orbital forcing during the LIG compared to the PIG (Fig. 1) puts a stronger constraint on the evolution of surface temperature such that biases associated with heat exchange with the deep ocean have a weaker impact. However, a significant role for ocean initialization of the transient PIG and LIG runs in determining accelerated vs. non-accelerated biases cannot be ruled out either (see next paragraph). The stronger insolation forcing of the LIG compared to the PIG is also evident in the temporal evolution of global precipitation patterns as derived from the EOF analysis: about $65 \%$ of the precipitation variance during the LIG is related to orbital forcing (and spreading over the leading two EOFs), whereas only ca. $31 \%$ of the precipitation variance is associated with orbital forcing during the PIG (and only contained in the first EOF). We note that orbital variations do not show up in higher modes either.

In accelerated simulations, temperature changes in the slowly adjusting deep ocean with its huge heat reservoir are damped and delayed relative to their non-accelerated counterparts. This global-scale delayed response affects seasurface temperatures at high latitudes. A deep-ocean cooling trend in the non-accelerated PIG run is not equally simulated in the accelerated run (Fig. 2e). As a result, the deep ocean has a warm bias throughout the Holocene in the accelerated simulation, which has a counterpart at the surface in high latitudes (Figs. 2a and 3c). Similarly, a cold deep-ocean bias during the late LIG in the accelerated run (Fig. 2f) has a surface counterpart at high southern latitudes (Figs. 2b and 3f). Previous studies conducted to test the effects of acceleration techniques in the boundary conditions on climate simulations using EMICs came to similar conclusions regarding sea-surface temperature biases at high latitudes (Lunt et al., 2006; Timm and Timmermann, 2007). In these regions, inappropriate deep-ocean initial conditions may severely compromise accelerated runs, strongly determining the climate trajectories. This becomes evident from the fact that the deep ocean has an adjustment timescale in the order of 1000 years or longer, which implies that the entire accelerated integration of an interglacial (using an acceleration factor of 10) is influenced by the initialization. In particular, we suggest that a considerable portion of the long-term deep-ocean cooling/warming trend in the accelerated PIG/LIG run (Fig. 2e and f) may be related to an adjustment to an imbalance be- 

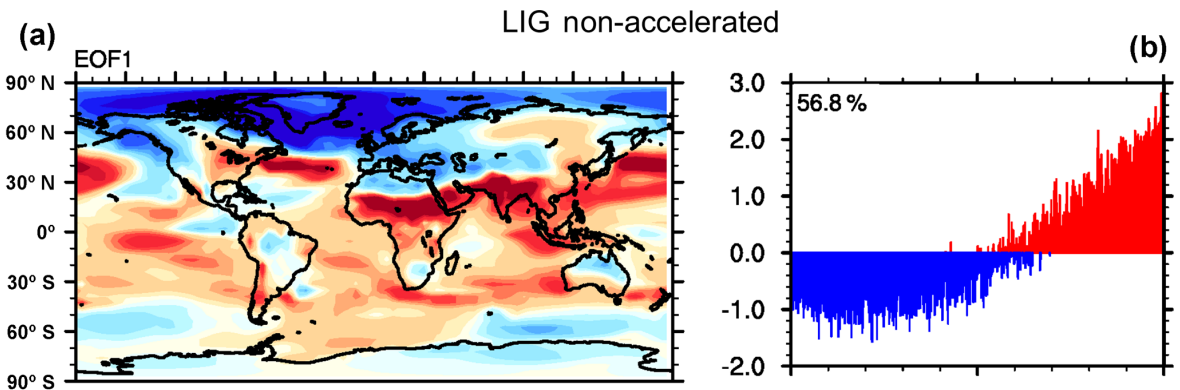

(c) EOF2

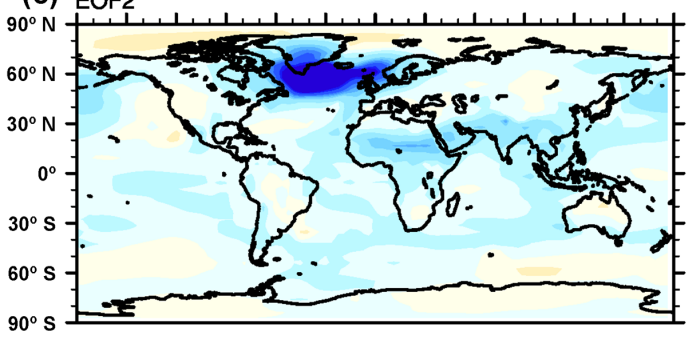

(d)

LIG accelerated

(e)

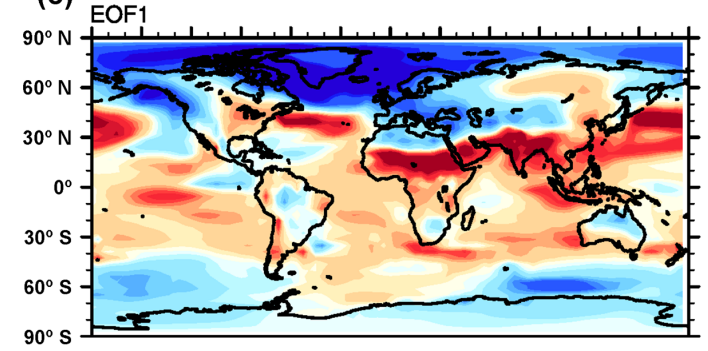

(g)
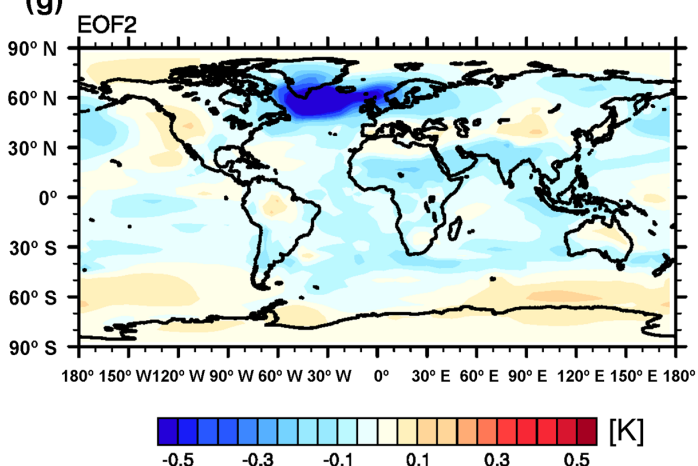

(f)

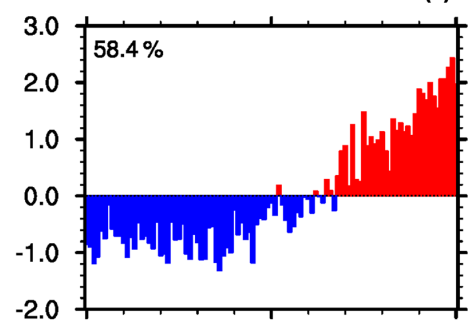

(h)

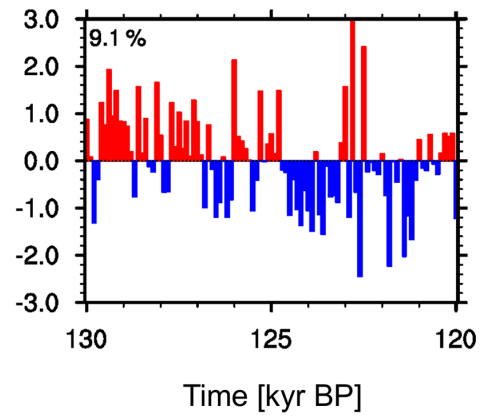

Figure 7. Same as Fig. 5 but for LIG surface temperature.

tween the initial state and the applied boundary conditions at the beginning of the transient simulation.

Biased sea-surface temperatures may affect the dynamics of the overlying atmosphere. In our simulations, such an effect was particularly pronounced in the PIG runs for the SWW, which are influenced by Southern Ocean temperatures, but also for the Northern Hemisphere westerly wind belt. In low latitudes, where the ocean is well stratified and does not exchange with the deep ocean, the effect of orbital acceleration on surface winds and (monsoonal) rainfall is negligible (cf. Govin et al., 2014).

Our transient interglacial simulations were forced by changes in orbital parameters and associated insolation only. Other forcing factors, in particular atmospheric greenhouse gas concentrations, were kept constant. However, there is no reason to assume that acceleration would affect the simulated climate response to slowly varying greenhouse gas (longwave) radiative forcing in a much different way than varying 
LIG non-accelerated
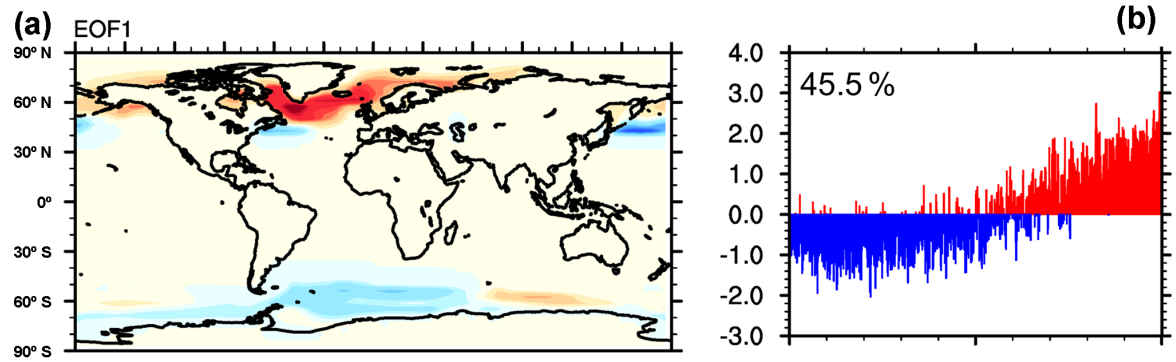

(c) EOF2

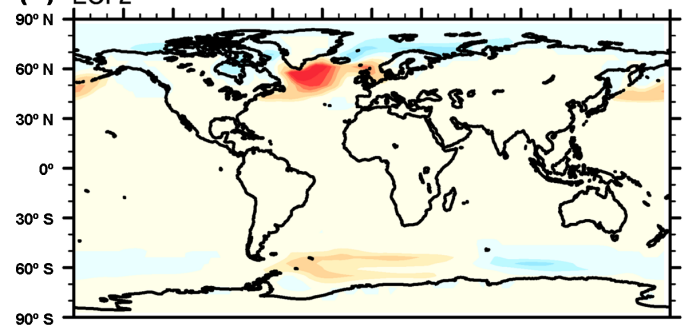

(d)

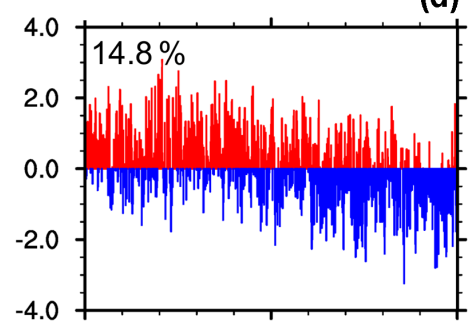

LIG accelerated

(e)
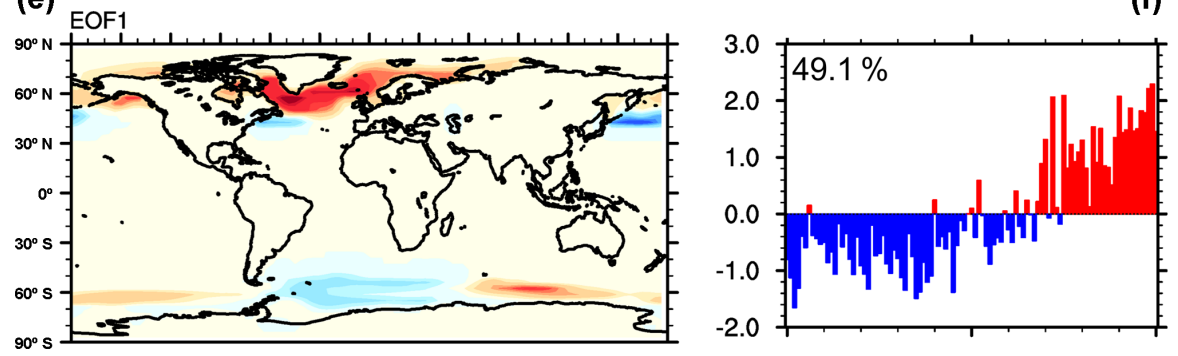

(g) EOF2
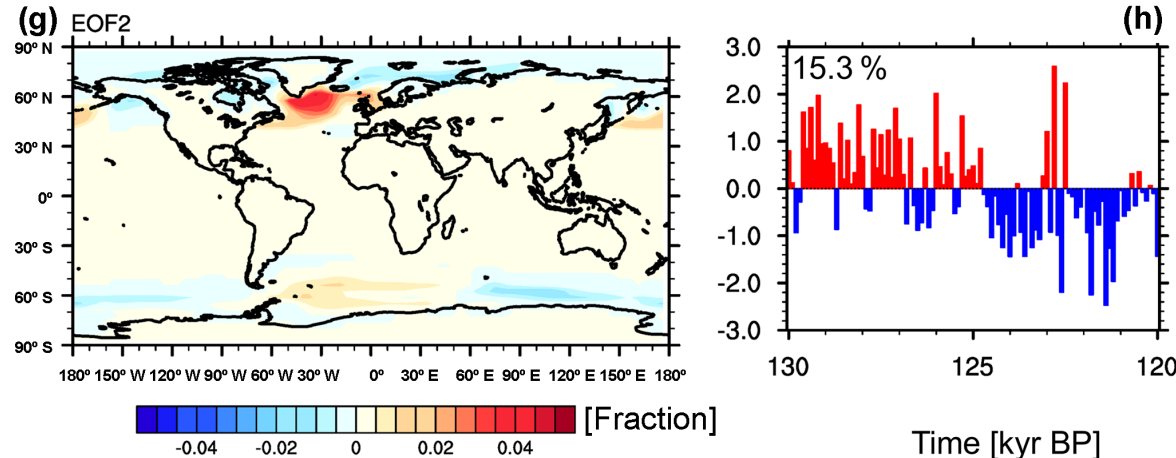

[Fraction]

Time [kyr BP]

Figure 8. Same as Fig. 5 but for LIG sea-ice concentration.

orbital (shortwave) radiative forcing. Hence, our conclusions for the acceleration of orbital forcing should also hold true for greenhouse gas forcing.

Acceleration techniques have been invented for the study of forced long-term (e.g. orbital-scale) climate variations, which is the focus of the present study. Still, we would like to mention that accelerated simulations also offer the possibility to study high-frequency (e.g. interannual) internal climate variability and its change through time. For this purpose, the simulated time series should be analysed on the model time axis rather than the orbital time axis. Assuming that the impact of orbital forcing on climate variability is minor on the $<1000$-year timescale, the effect of orbital forcing is minor on century-scale intervals on the model time axis of a 10-fold accelerated run. For reasonable statistics, a sufficient number of climate cycles should occur within these centennial intervals, which would allow for the study of interannual- 
(a)

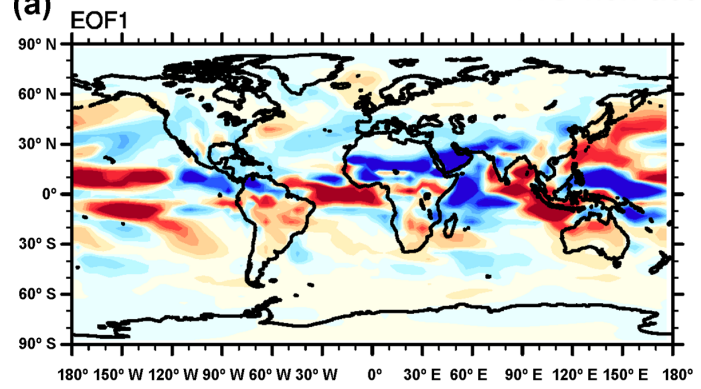

(c)

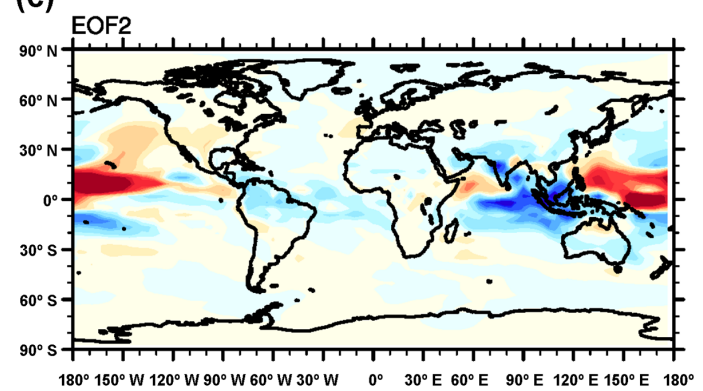

PIG non-accelerated

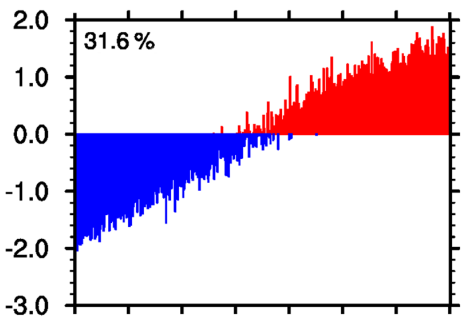

(d)

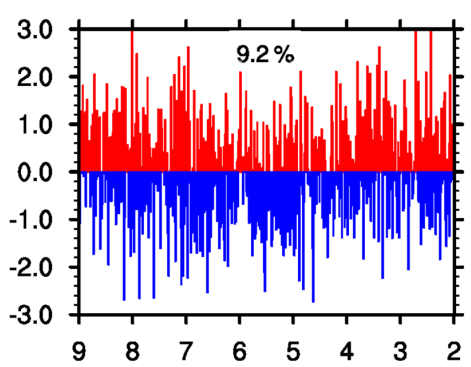

PIG accelerated

(6)



(g)
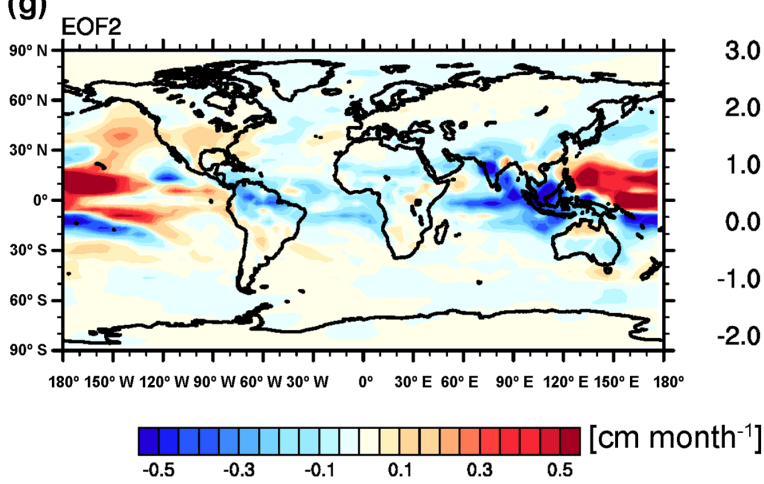

(f)

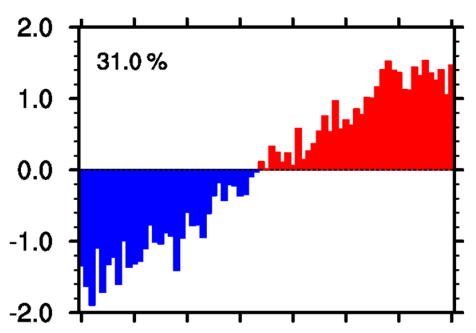

(h)

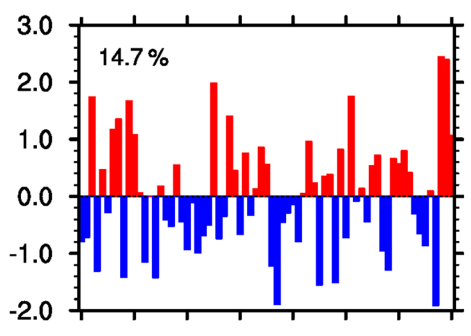

Time $[k y r$ BP]

Figure 9. Same as Fig. 5 but for PIG precipitation.

to-decadal variability, and its change through time (on the orbital time axis), in 10-fold accelerated simulations.

In summary, it can be stated that results from accelerated interglacial CGCM simulations are meaningful when lowlatitude climate is considered. In these regions, the acceleration technique does not hamper model intercomparison nor model-data comparison studies, such as Bakker et al. (2013,
2014) and Kwiatkowski et al. (2015), in which accelerated simulations have been employed. In high latitudes, however, the use of acceleration techniques can substantially affect the surface temperature such that acceleration should be avoided in studies of extratropical climate change. 

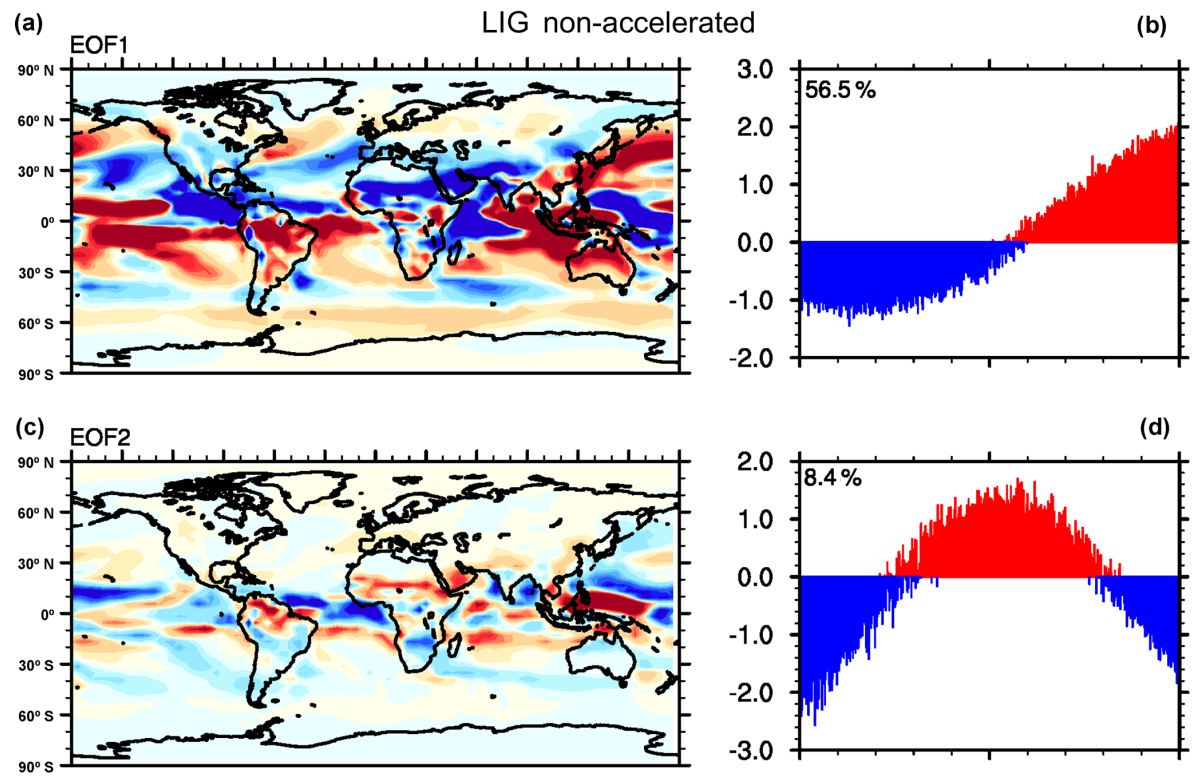

LIG accelerated
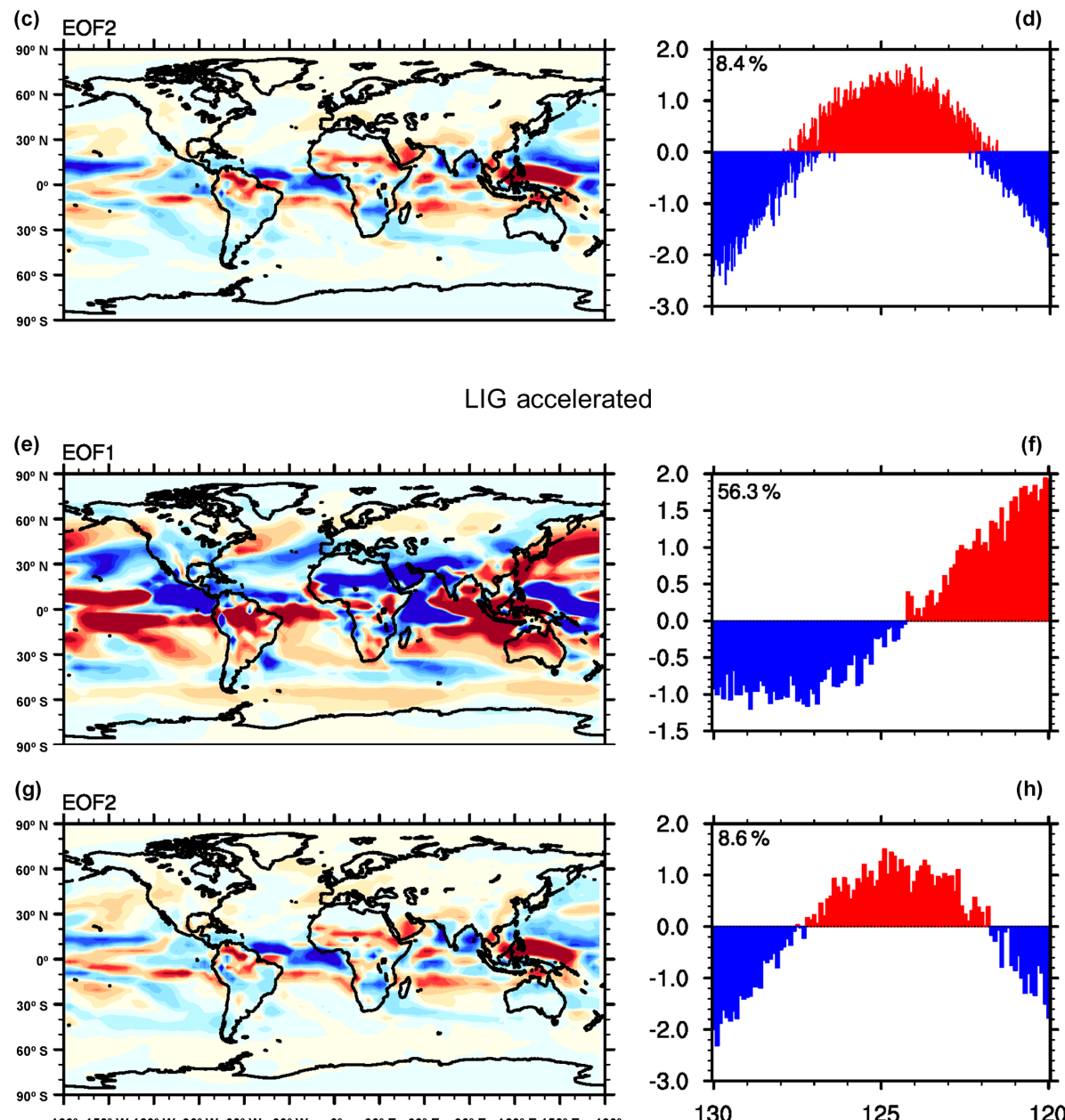

(d)

(h)
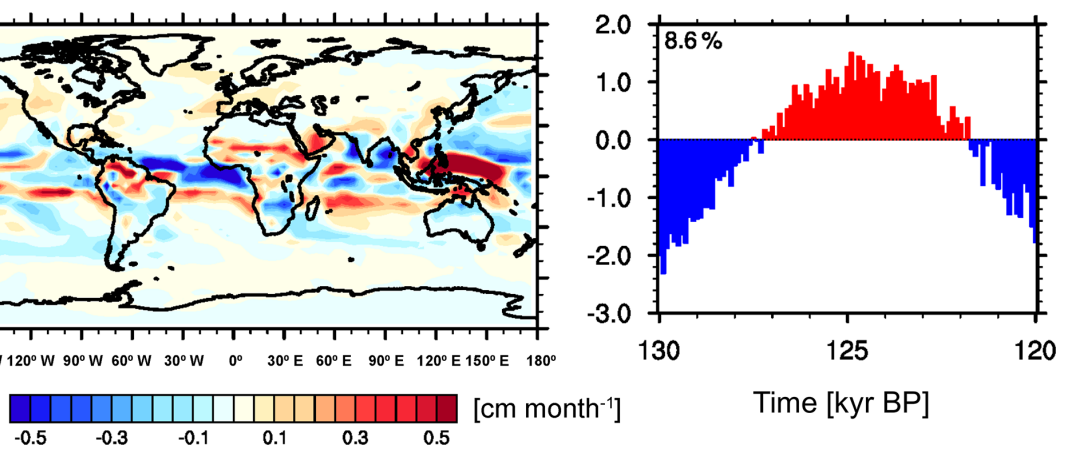

Figure 10. Same as Fig. 5 but for LIG precipitation.

\section{Conclusions}

Transient simulations from a fully coupled comprehensive climate model have been analysed to study the effects of orbital acceleration on the present and last interglacial climates. To this end, simulations were carried out both with and without orbital acceleration. Comparison of the results from these simulations shows that in low latitudes the simulation of long-term variations in interglacial surface climate is not sig- nificantly affected by the use of the acceleration technique (with an acceleration factor of 10) and hence model-data comparison of surface variables is therefore not hampered. However, due to the long adjustment time of the deep ocean with its huge heat reservoir, major repercussions of the orbital forcing are obvious below the thermocline. As a result, acceleration-induced biases in sea-surface temperature evolution arise in high-latitude regions where the surface climate has a direct connection to the deep ocean (upwelling of deep 


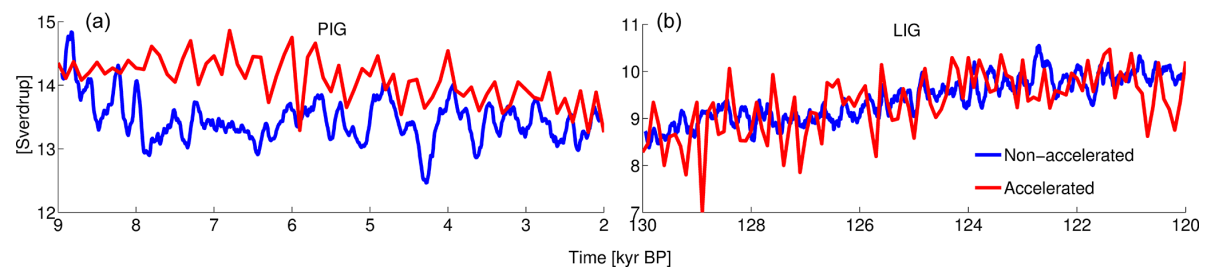

Figure 11. Temporal evolution of the AMOC (given as the maximum of the North Atlantic overturning stream function) during both the interglacials for both non-accelerated (blue) and accelerated (red) simulations. All plots were created using the decadal mean values (referring to model years). In addition, a 10-point running average was applied to the decadal mean values of the non-accelerated simulations.

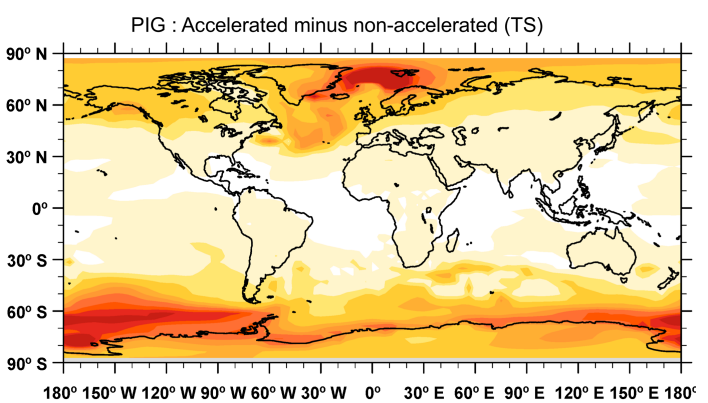

LIG : Accelerated minus non-accelerated (TS)

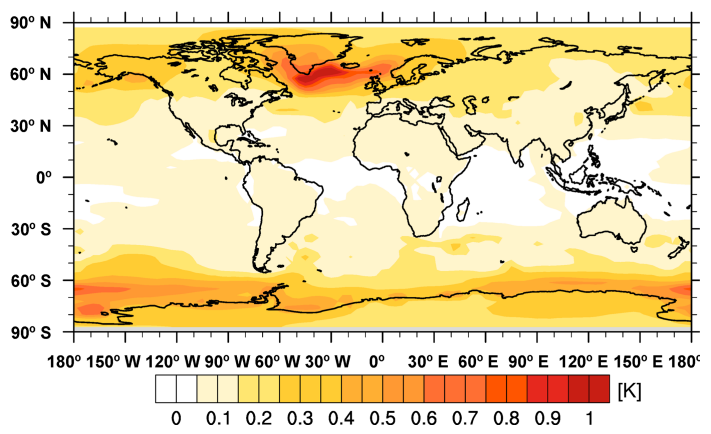

Figure 12. Root mean square difference between accelerated and non-accelerated simulations for surface temperature (TS). All plots were created using the decadal mean values (referring to model years). Ten-point bins are used for the non-accelerated run to have the same number of data points on the time axis as in the accelerated simulation. An additional 1000-orbital-year filter has been applied to both accelerated and non-accelerated time series to remove noise. Due to these low-pass filtering only the long-term (orbital-forced) trend variability is considered by the root mean square deviations.

water in the Southern Ocean, deep convection regions at high latitudes). Sea-ice feedbacks amplify the temperature biases. In these regions, the climate trajectory can be crucially determined by the deep-ocean initialization of the accelerated transient simulation. It was further found that the temporal evolution of the southern and northern westerlies could be affected by sea-surface temperature biases. To conclude, the accelerated simulations suffer from a smoothed and delayed deep-ocean response to the forcing and are overly controlled by the initial state of the deep ocean. This may compromise transient climate simulations over large regions in the extrat- ropics, such that special care has to be taken or acceleration should be avoided.

\section{Data availability}

The data for this study are currently available in the PANGAEA database. The DOI is https://doi.pangaea.de/10.1594/ PANGAEA.867327 (Varma et al., 2016). The model source code along with the required input/forcing files is openly available for public access at https://www.earthsystemgrid. org/dataset/ucar.cgd.ccsm.src.3.0.0.html.

Acknowledgements. We are grateful to Oliver Elison Timm, Didier Roche and two anonymous reviewers for their very constructive comments. The climate model used in this study is the Community Climate System Model version 3 (CCSM3), which is maintained at the National Center for Atmospheric Research (NCAR). The CCSM3 simulations were performed on the SGI Altix supercomputer of the Norddeutscher Verbund für Hoch- und Höchstleistungsrechnen (HLRN). This work was funded through the DFG Priority Research Program INTERDYNAMIK and the European Union's Seventh Framework Programme (FP7/2007-2013) under grant agreement 243908, Past4Future: Climate change - Learning from the past climate.

The article processing charges for this open-access publication were covered by the University of Bremen.

Edited by: D. Roche

Reviewed by: O. Elison Timm and two anonymous referees 


\section{References}

Bakker, P., Stone, E. J., Charbit, S., Gröger, M., Krebs-Kanzow, U., Ritz, S. P., Varma, V., Khon, V., Lunt, D. J., Mikolajewicz, U., Prange, M., Renssen, H., Schneider, B., and Schulz, M.: Last interglacial temperature evolution - a model inter-comparison, Clim. Past, 9, 605-619, doi:10.5194/cp-9-605-2013, 2013.

Bakker, P., Masson-Delmotte, V., Martrat, B., Charbit, S., Renssen, H., Gröger, M., Krebs-Kanzow, U., Lohman, G., Lunt, D. J., Pfeiffer, M., Phipps, S. J., Prange, M., Ritz, S. P., Schulz, M., Stenni, B., Stone, E. J., and Varma, V.: Temperature trends during the Present and Last Interglacial periods - a multimodel-data comparison, Quaternary Sci. Rev., 99, 224-243, doi:10.1016/j.quascirev.2014.06.031, 2014.

Berger, A. L.: Long-term variations of daily insolation and Quaternary climatic changes, J. Atmos. Sci., 35, 2362-2367, doi:10.1175/1520-0469(1978)035<2362:LTVODI>2.0.CO;2, 1978.

Braconnot, P., Otto-Bliesner, B., Harrison, S., Joussaume, S., Peterchmitt, J.-Y., Abe-Ouchi, A., Crucifix, M., Driesschaert, E., Fichefet, T., Hewitt, C. D., Kageyama, M., Kitoh, A., Laîné, A., Loutre, M.-F., Marti, O., Merkel, U., Ramstein, G., Valdes, P., Weber, S. L., Yu, Y., and Zhao, Y.: Results of PMIP2 coupled simulations of the Mid-Holocene and Last Glacial Maximum Part 1: experiments and large-scale features, Clim. Past, 3, 261277, doi:10.5194/cp-3-261-2007, 2007.

Claussen, M., Mysak, L. A., Weaver, A. J., Crucifix, M., Fichefet, T., Loutre, M.-F., Weber, S. L., Alcamo, J., Alexeev, V. A., Berger, A., Calov, R., Ganopolski, A., Goosse, H., Lohmann, G., Lunkeit, F., Mokhov, I. I., Petoukhov, V., Stone, P., and Wang, Z.: Earth system models of intermediate complexity: closing the gap in the spectrum of climate system models, Clim. Dynam., 18, 579-586, 2002.

Collins, W. D., Bitz, C. M., Blackmon, M. L., Bonan, G. B., Bretherton, C. S., Carton, J. A., Chang, P., Doney, S. C., Hack, J. J., Henderson, T. B., Kiehl, J. T., Large, W. G., McKenna, D. S., Santer, B. D., and Smith, R. D.: The Community Climate System Model Version 3 (CCSM3), J. Climate, 19, 2122-2143, doi:10.1175/JCLI3761.1, 2006.

Govin, A., Varma, V., and Prange, M.: Astronomically forced variations in western African rainfall $\left(21^{\circ} \mathrm{N}-20^{\circ} \mathrm{S}\right)$ during the Last Interglacial period, Geophys. Res. Lett., 41, 2117-2125, doi:10.1002/2013GL058999, 2014.

Kwiatkowski, C., Prange, M., Varma, V., Steinke, S., Hebbeln, D., and Mohtadi, M.: Holocene variations of thermocline conditions in the eastern tropical Indian Ocean, Quaternary Sci. Rev., 114, 33-42, doi:10.1016/j.quascirev.2015.01.028, 2015.

Liu, Z., Zhu, J., Rosenthal, Y., Zhang, X., Otto-Bliesner, B. L., Timmermann, A., Smith, R. S., Lohmann, G., Zheng, W., and Elison Timm, O.: The Holocene temperature conundrum, P. Natl. Acad. Sci. USA, 111, E3501-E3505, doi:10.1073/pnas.1407229111, 2014.

Lorenz, S. J. and Lohmann, G.: Acceleration technique for Milankovitch type forcing in a coupled atmosphere-ocean circulation model: method and application for the Holocene, Clim. Dynam., 23, 727-743, 2004.

Loulergue, L., Schilt, A., Spahni, R., Masson-Delmotte, V., Blunier, T., Lemieux, B., Barnola, J.-M., Raynaud, D., Stocker, T. F., and Chappellaz, J.: Orbital and millennial-scale features of atmospheric $\mathrm{CH}_{4}$ over the past 800,000 years, Nature, 453, 383386, doi:10.1038/nature06950, 2008.

Loutre, M.-F., Paillard, D., Vimeux, F., and Cortijo, E.: Does mean annual insolation have the potential to change the climate?, Earth Planet. Sc. Lett., 221, 1-14, 2004.

Lunt, D. J., Williamson, M. S., Valdes, P. J., Lenton, T. M., and Marsh, R.: Comparing transient, accelerated, and equilibrium simulations of the last 30000 years with the GENIE-1 model, Clim. Past, 2, 221-235, doi:10.5194/cp-2-221-2006, 2006.

Lunt, D. J., Abe-Ouchi, A., Bakker, P., Berger, A., Braconnot, P., Charbit, S., Fischer, N., Herold, N., Jungclaus, J. H., Khon, V. C., Krebs-Kanzow, U., Langebroek, P. M., Lohmann, G., Nisancioglu, K. H., Otto-Bliesner, B. L., Park, W., Pfeiffer, M., Phipps, S. J., Prange, M., Rachmayani, R., Renssen, H., Rosenbloom, N., Schneider, B., Stone, E. J., Takahashi, K., Wei, W., Yin, Q., and Zhang, Z. S.: A multi-model assessment of last interglacial temperatures, Clim. Past, 9, 699-717, doi:10.5194/cp-9-699-2013, 2013.

Lüthi, D., Le Floch, M., Bereiter, B., Blunier, T., Barnola, J.-M., Siegenthaler, U., Raynaud, D., Jouzel, J., Fischer, H., and Kawamura, K., and Stocker, T. F.: High-resolution carbon dioxide concentration record $650,000-800,000$ years before present, Nature, 453, 379-382, doi:10.1038/nature06949, 2008.

Merkel, U., Prange, M., and Schulz, M.: ENSO variability and teleconnections during glacial climates, Quaternary Sci. Rev., 29, 86-100, doi:10.1016/j.quascirev.2009.11.006, 2010.

Milker, Y., Rachmayani, R., Weinkauf, M. F. G., Prange, M., Raitzsch, M., Schulz, M., and Kucera, M.: Global and regional sea surface temperature trends during Marine Isotope Stage 11, Clim. Past, 9, 2231-2252, doi:10.5194/cp-9-2231-2013, 2013.

Otto-Bliesner, B. L., Russell, J. M., Clark, P. U., Liu, Z., Overpeck, J. T., Konecky, B., deMenocal, P., Nicholson, S. E., He, F., and $\mathrm{Lu}, \mathrm{Z}$.: Coherent changes of southeastern equatorial and northern African rainfall during the last deglaciation, Science, 346, 1223 1227, 2014.

Rachmayani, R., Prange, M., and Schulz, M.: Intra-interglacial climate variability: model simulations of Marine Isotope Stages 1, 5, 11, 13, and 15, Clim. Past, 12, 677-695, doi:10.5194/cp-12677-2016, 2016.

Schneider, T., Bischoff, T., and Haug, G. H.: Migrations and dynamics of the intertropical convergence zone, Nature, 513, 4553, 2014.

Smith, R. and Gregory, J.: The last glacial cycle: transient simulations with an AOGCM, Clim. Dynam., 38, 1545-1559, doi:10.1007/s00382-011-1283-y, 2012.

Spahni, R., Chappellaz, J., Stocker, T. F., Loulergue, L., Hausammann, G., Kawamura, K., Fluckiger, J., Schwander, J., Raynaud, D., Masson-Delmotte, V., and Jouzel, J.: Atmospheric Methane and Nitrous Oxide of the Late Pleistocene from Antarctic Ice Cores, Science, 310, 1317-1321, 2005.

Timm, O. and Timmermann, A.: Simulation of the last 21,000 years using accelerated transient boundary conditions, J. Climate, 20, 4377-4401, 2007.

Timmermann, A., Friedrich, T., Elison Timm, O., Chikamoto, M. O., Abe-Ouchi, A., and Ganopolski, A.: Modeling Obliquity and $\mathrm{CO}_{2}$ Effects on Southern Hemisphere Climate during the Past 408 ka, J. Climate, 27, 1863-1875, doi:10.1175/JCLI-D-1300311.1, 2014. 
Varma, V., Prange, M., Merkel, U., Kleinen, T., Lohmann, G., Pfeiffer, M., Renssen, H., Wagner, A., Wagner, S., and Schulz, M.: Holocene evolution of the Southern Hemisphere westerly winds in transient simulations with global climate models, Clim. Past, 8, 391-402, doi:10.5194/cp-8-391-2012, 2012.

Varma, V., Prange, M., and Schulz, M.: Transient simulations for present and last interglacials using a comprehensive coupled climate model CCSM3 (Community Climate System Model 3.0), links to model result files in NetCDF format, doi:10.1594/PANGAEA.867327, 2016.
Voigt, I., Chiessi, C. M., Prange, M., Mulitza, S., Groeneveld, J., Varma, V., and Henrich, R.: Holocene shifts of the southern westerlies across the South Atlantic, Paleoceanography, 30, 39-51, doi:10.1002/2014PA002677, 2015.

von Storch, H. and Zwiers, F. W.: Statistical Analysis in Climate Research, Cambridge University Press, Cambridge, 2004.

Yeager, S. G., Shields, C. A., Larger, W. G., and Hack, J. J.: The low-resolution CCSM3, J. Climate, 19, 2545-2566, doi:10.1175/JCLI3744.1, 2006. 